\title{
Minimally invasive colorectal surgery in the morbid obese: does size really matter?
}

\author{
Sofoklis Panteleimonitis ${ }^{1,2}$ C $\cdot$ Sotirios Popeskou ${ }^{2} \cdot$ Mick Harper $^{1} \cdot$ Ngianga Kandala $^{1} \cdot$ Nuno Figueiredo $^{3}$. \\ Tahseen Qureshi ${ }^{2,4} \cdot$ Amjad Parvaiz ${ }^{1,2,3}$
}

Received: 8 August 2017 / Accepted: 12 January 2018 / Published online: 23 January 2018

(c) The Author(s) 2018. This article is an open access publication

\begin{abstract}
Background As obesity becomes more prevalent, it presents a technical challenge for minimally invasive colorectal resection surgery. Various studies have examined the clinical outcomes of obese surgical patients. However, morbidly obese patients $(B M I \geq 35)$ are becoming increasingly more common. This study aims to investigate the short-term surgical outcomes of morbidly obese patients undergoing minimal-invasive colorectal surgery and compare them with both obese $(30 \leq \mathrm{BMI}<35)$ and non-obese patients (BMI <30).

Methods Patients from three centres who received minimally invasive colorectal surgical resections between 2006 and 2016 were identified from prospectively collected databases. The baseline characteristics and surgical outcomes of morbidly obese, obese and non-obese patients were analysed.

Results A total of 1386 patients were identified, 84 (6\%) morbidly obese, $246(18 \%)$ obese and 1056 (76\%) non-obese. Patients' baseline characteristics were similar for age, operating surgeon, surgical approach but differed in terms of ASA grade and gender. There was no difference in conversion rate, length of stay, anastomotic leak rate and 30-day readmission, reoperation and mortality rates. Operation time and blood loss were different across the 3 groups (morbidly obese vs obese vs non-obese: 185 vs 188 vs $170 \mathrm{~min}, p=0.000 ; 20$ vs $20 \mathrm{vs} 10 \mathrm{ml}, p=0.003$ ). In patients with malignant disease there was no difference in lymph node yield or R0 clearance. Univariate and multivariate linear regression analysis showed that for every one-unit increase in BMI operative time increases by roughly 2 min (univariate 2.243, 95\% CI 1.524-2.962; multivariate 2.295 ; 95\% CI 1.554-3.036). Univariate and multivariate binary logistic regression analyses showed that BMI does not affect conversion or morbidity and mortality.

Conclusions The increased technical difficulty encountered in obese and morbidly obese patients in minimally invasive colorectal surgery results in higher operative times and blood loss, although this is not clinically significant. However, conversion rate and post-operative short-term outcomes are similar between morbidly obese, obese and non-obese patients.
\end{abstract}

Keywords Minimally invasive $\cdot$ Laparoscopic $\cdot$ Colorectal surgery $\cdot$ Obese

Sofoklis Panteleimonitis

sofoklis_p@hotmail.com

1 School of Health Sciences and Social Work, University of Portsmouth, James Watson West, 2 King Richard 1st road, Portsmouth PO1 2FR, UK

2 Poole Hospital NHS Trust, Longfleet road, Poole BH15 2JB, UK

3 Champalimaud Foundation, Av. Brasilia, 1400-038 Lisbon, Portugal

4 Bournemouth University School of Health and Social Care, Bournemouth, UK
Minimally invasive surgery (MIS) has become the new standard for colorectal diseases in the developed world, and its benefits such as shorter hospital stay, less post-operative pain, early mobilisation and improved cosmesis are well established [1-6]. These benefits are crucial for high-risk groups of patients such as the clinically obese who's presentation is clearly linked with several comorbidities such as diabetes mellitus and cardiovascular disease in addition to higher risks of suffering from surgical site infections and pulmonary embolisms [7]. Based on this, it is speculated that a less invasive approach to surgery would be optimal for this group of patients [8]. 
Although obese patients have much to gain from a minimally invasive approach to colorectal surgery, the increased amount of visceral fat encountered in obese patients increases the technical difficulty of surgery [8]. Obese patients often have a thickened and excessive omentum and mesentery which restricts access, distorts the surgical planes and can result in problematic bleeding [9]. Whether the increased technical difficulty encountered in this group of patients leads to higher conversion rates and worse shortterm outcomes is a subject of debate. For example, studies have examined the short-term outcomes of obese patients in laparoscopic colorectal surgery with many reporting inferior short-term outcomes in the obese [10-12] while others demonstrating similar outcomes between obese and non-obese patients [13, 14].

An ageing population, austerity and lifestyle choices are causing a rise in obesity causing health and care challenges as well as high costs to the economy. In the US more than one-third of the population is reported to be obese and in the UK obesity prevalence has risen from $15 \%$ in 1993 to $26 \%$ in $2014[15,16]$. In addition to this, morbidly obese patients are becoming increasingly more common. According to an English report by the Health and Social Care Information Centre (2016) on the Statistics on Obesity, Physical Activity and Diet [16], in England in 2014 2\% of men and 4\% of women had a BMI of 40 or higher. This number has tripled over the last 25 years and presents a worrying picture, but in comparison, the USA reports $5 \%$ of the population is believed to be morbidly obese [15]. Therefore, the technical challenges discussed above for obese patients are magnified when considering minimally invasive surgery on morbidly obese patients where the risks encountered in this group of patients are even greater, due to the ever-greater amount of visceral fat encountered in the abdomen further restricting the space for manoeuvre during surgery and making it hard to define the surgical planes. Despite this, the surgical outcomes of this group of patients are poorly examined as most studies compare the outcomes of obese $(\mathrm{BMI} \geq 30)$ vs non-obese patients $(\mathrm{BMI}<30)$.

The study reported here aims to investigate the short-term surgical outcomes of morbidly obese $(\mathrm{BMI} \geq 35)$ patients undergoing minimally invasive colorectal resection surgery and compare them to those of obese $(30 \leq \mathrm{BMI}<35)$ and non-obese $(\mathrm{BMI}<30)$ patients. This study presents the biggest European series examining morbidly obese patients receiving minimally invasive colorectal resection surgery.

\section{Materials and methods}

Consecutive patients from three centres, two from the UK and one from Portugal, who received minimally invasive colorectal surgical resections between 2006 and 2016 were identified from prospectively collected databases. All patients whose BMI was reported were included in the study. Patients were categorised as morbidly obese (BMI $\geq 35$ ), obese $(30 \leq \mathrm{BMI}<35)$ and non-obese $(\mathrm{BMI}<30)$ in accordance with the NIH conference [17].

Patients were included in the study irrespective of indication for surgery and obesity or morbid obesity was not considered a contraindication for minimally invasive surgery. All cancer patients were discussed in the multidisciplinary team meeting. Surgery was laparoscopic or robotic, with the robotic approach being preferred for all rectal surgery since the acquisition of the robot in each unit. Applied surgical modality was based on surgeon preference and equipment availability. Informed consent was obtained from all patients prior to inclusion to this study. The requirements for anonymization of personal dataset by the Data Protection Act 1998 were satisfied. According to the Health Research Authority (HRA), this study was not classified to need their approval as it is an audit.

Patients included in the study had surgery performed by three colorectal surgeons, one surgeon in each centre. Data collection began when the surgeons participating in this study started working in their respective units, between 2006 and 2012 for the UK centres and 2013 for the Portuguese centre. All surgeons applied a modular, standardised previously described approach to surgery [18-20].

Post-operative care was standardised, with patients entering a routine enhanced recovery programme based on the one described by Kehlet and Wilmore [21]. Patients were discharged home when their condition was assessed as meeting set criteria for discharge.

\section{Data collection and outcome assessment}

All data were collected from prospectively collated databases. The baseline characteristics and surgical outcomes of morbidly obese, obese and non-obese patients were analysed. Baseline characteristics analysed were age, gender, ASA grade, diagnosis (malignant vs benign), mode (elective vs emergency), surgical approach (laparoscopic vs robotic), operating surgeon, operation performed and $\mathrm{T}$ stage (for malignant disease). Perioperative data included operative time, estimated blood loss and conversion to open (defined as any incision needed to either mobilise the colon or rectum or ligate the vessels). Post-operative clinical data examined included length of stay, 30-day readmission, 30-day reoperation, 30-day mortality and anastomotic leak. For malignant disease cases lymph node yield and circumferential resection margin (CRM) clearance were examined. Two subgroup analyses were performed. Morbidly obese patients with a $\mathrm{BMI} \geq 40$ were compared with patients whose BMI was $\geq 35$ and $<40$. Moreover, subgroup analyses of patients 
receiving right colonic, left colonic and rectal resections was performed.

\section{Statistical analysis}

Data were analysed using IBM SPSS version 22 (SPSS Inc., Chicago, IL, USA). Non-parametric data were expressed as median with interquartile range and parametric data as mean with standard deviation. Baseline demographic and clinical characteristics were compared using $\chi^{2}$ test for categorical variables, Kruskal-Wallis test for non-parametric continuous variables and one-way ANOVA for parametric continuous variables. $P$ values of $<0.05$ were considered statistically significant. Univariate binary logistic regression analysis was performed to assess whether BMI affected conversion to open or morbidity and mortality, with morbidity and mortality defined as the presence of any of the following outcomes: 30-day reoperation, 30-day readmission, anastomotic leak and 30-day mortality. Following this, a multivariate model was applied were BMI was adjusted for all clinically relevant variables. Finally, a univariate and multivariate linear regression model was applied to investigate the effect of BMI on operative time. Since both BMI and operation time were non-parametric, Spearman's rank correlation was calculated to evaluate the correlation.

\section{Results}

A total of 1386 patients underwent minimally invasive colorectal resection surgery by a surgeon from each study site. Of those, $84(6 \%)$ were morbidly obese, $246(18 \%)$ obese and 1056 (76\%) non-obese.

\section{Baseline characteristics}

The baseline characteristics of the three groups are summarised in Table 1. Patient baseline characteristics were similar for age, diagnosis, operating surgeon, surgical approach and $\mathrm{T}$ stage but differed in terms of ASA grade, gender and mode of surgery.

As expected ASA grade was worse in the morbidly obese group. There were more female patients in the morbidly obese group and less in the obese group compared to the non-obese group (female patients in morbidly obese vs obese vs non-obese: $58.3 \%$ vs $38.6 \%$ vs $46.7 \%$; $p=0.005$ ). The obese group had the least amount of patients receiving emergency surgery and the non-obese group the most (morbidly obese vs obese vs non-obese: $2.4 \%$ vs $0.8 \%$ vs $3.9 \%$; $p=0.045)$. The operative procedures performed across the 3 groups are summarised in Table 2 .

\section{Perioperative characteristics and outcomes}

The perioperative characteristics of the three groups are summarised in Table 3. Operation time and blood loss were different across the three cohorts (morbidly obese vs obese vs non-obese: median operation time 185 vs 188 vs $170 \mathrm{~min}$, $p=0.000$; median estimated blood loss 20 vs 20 vs $10 \mathrm{ml}$, $p=0.003)$. Conversion rate was similar across the three groups with an overall conversion rate of $1.2 \%(p=0.251)$.

\section{Post-operative clinical and pathological outcomes}

There were no differences in any of the post-operative clinical outcomes (length of stay, 30-day readmission rate, 30-day reoperation rate, anastomotic leak rate, 30-day mortality rate) or pathological outcomes (lymph node yield and CRM clearance) between the three cohorts as summarised in Table 4.

\section{Logistic and linear regression analysis}

Univariate logistic regression analysis showed that BMI did not affect conversion to open for the participants in this study. This was still the case in multivariate analysis when other clinically relevant factors were adjusted for (age, ASA grade, mode of surgery, diagnosis). Findings are summarised in Table 5. Furthermore, univariate logistic regression analysis (Table 6) showed that BMI did not affect morbidity and mortality. This was still the case in multivariate analysis when other clinically relevant factors were adjusted for (age, ASA grade, mode of surgery, diagnosis).

There was however, a weak but significant correlation between BMI and operative time (Spearman's $\rho=0.182 ; p=0.000)$. Univariate linear regression analysis showed that for every one-unit increase in BMI operative time increases by roughly $2 \min (b=2.243,95 \%$ CI $1.524-2.962 ; p=0.000)$. This was still the case in multivariate analysis when other clinically relevant factors were considered (ASA grade, mode of surgery) $(b=2.295,95 \%$ CI $1.554-3.036 ; p=0.000)$. Findings are summarised in Table 7. Figure 1 represents the scatter plot of BMI against operative time.

\section{Subgroup analyses}

\section{Patients with $35 \leq \mathrm{BMI}<40$ vs $\mathrm{BMI} \geq 40$}

There were 64 patients with a BMI between 35 and 40 and 20 with a BMI equal or greater than 40 . Patients with a $\mathrm{BMI} \geq 40$ were younger ( 66 vs $59.5 ; p=0.044$ ). There were no other significant differences in any of the baseline characteristics or short-term surgical outcomes between the two groups. Operation time appeared to be higher in the 
Table 1 Baseline characteristics

\begin{tabular}{|c|c|c|c|c|}
\hline & Non-obese $(n=1056)$ & $\begin{array}{l}\text { Obese } \\
(n=246)\end{array}$ & $\begin{array}{l}\text { Morbidly obese } \\
(n=84)\end{array}$ & $p$ value \\
\hline Median BMI & $25(22.7-27)$ & $31(30-32)$ & $36(35.1-39)$ & $0.000^{\mathrm{a}}$ \\
\hline Median age & $68(58-77)$ & $65(58.2-73.9)$ & $65(58-72.2)$ & $0.056^{\mathrm{a}}$ \\
\hline \multicolumn{5}{|l|}{ Gender } \\
\hline Male & $563(53.3 \%)$ & $151(61.4 \%)$ & $35(41.7 \%)$ & \multirow[t]{2}{*}{$0.005^{\mathrm{b}}$} \\
\hline Female & $493(46.7 \%)$ & $95(38.6 \%)$ & $49(58.3 \%)$ & \\
\hline \multicolumn{5}{|l|}{ ASA grade } \\
\hline I & $159(15.4 \%)$ & $27(11.1 \%)$ & $3(3.7 \%)$ & \multirow[t]{4}{*}{$0.000^{b}$} \\
\hline II & $680(65.8 \%)$ & $164(67.5 \%)$ & $41(50 \%)$ & \\
\hline III & $191(18.5 \%)$ & $51(21 \%)$ & $37(45.1 \%)$ & \\
\hline IV & $4(0.4 \%)$ & $1(0.4 \%)$ & $1(1.2 \%)$ & \\
\hline \multicolumn{5}{|l|}{ Diagnosis } \\
\hline Malignant & $784(74.2 \%)$ & $193(78.5 \%)$ & $66(78.6 \%)$ & \multirow[t]{2}{*}{$0.297^{\mathrm{b}}$} \\
\hline Benign & $272(25.8 \%)$ & $53(21.5 \%)$ & $18(21.4 \%)$ & \\
\hline \multicolumn{5}{|l|}{ Mode of surgery } \\
\hline Elective & $1015(96.1 \%)$ & $244(99.2 \%)$ & $82(97.6 \%)$ & \multirow[t]{2}{*}{$0.045^{\mathrm{b}}$} \\
\hline Emergency & $41(3.9 \%)$ & $2(0.8 \%)$ & $2(2.4 \%)$ & \\
\hline \multicolumn{5}{|c|}{ Surgical approach } \\
\hline Laparoscopic & $979(92.7 \%)$ & $226(91.9 \%)$ & $81(96.4 \%)$ & \multirow[t]{2}{*}{$0.371^{b}$} \\
\hline Robotic & $77(7.3 \%)$ & $20(8.1 \%)$ & $3(3.6 \%)$ & \\
\hline \multicolumn{5}{|c|}{ Operating Surgeon } \\
\hline $\mathrm{A}$ & $778(73.7 \%)$ & $181(73.6 \%)$ & $64(76.2 \%)$ & \multirow[t]{3}{*}{$0.927^{\mathrm{b}}$} \\
\hline $\mathrm{B}$ & $30(2.8 \%)$ & $7(2.8 \%)$ & $1(1.2 \%)$ & \\
\hline $\mathrm{C}$ & $248(23.5 \%)$ & $58(23.6 \%)$ & $19(22.6 \%)$ & \\
\hline \multicolumn{5}{|l|}{ T stage } \\
\hline 0 & $29(3.8 \%)$ & $9(4.7 \%)$ & $2(3 \%)$ & \multirow[t]{5}{*}{$0.116^{\mathrm{b}}$} \\
\hline 1 & $70(9.1 \%)$ & $24(12.6 \%)$ & $6(9 \%)$ & \\
\hline 2 & $170(22.1 \%)$ & $43(22.6 \%)$ & $24(35.8 \%)$ & \\
\hline 3 & $397(51.6 \%)$ & $95(50 \%)$ & $32(47.8 \%)$ & \\
\hline 4 & $104(13.5 \%)$ & $19(10 \%)$ & $3(4.5 \%)$ & \\
\hline
\end{tabular}

Statistically significant values are given in bold

${ }^{a}$ Kruskal-Wallis Test

${ }^{\mathrm{b}}$ Chi-square

Table 2 Operative procedures

\begin{tabular}{llrl}
\hline & Non-obese $(n=1056)$ & Obese $(n=246)$ & $\begin{array}{l}\text { Morbidly } \\
\text { obese } \\
(n=84)\end{array}$ \\
\hline Right hemicolectomy & $280(26.5 \%)$ & $41(16.7 \%)$ & $16(19 \%)$ \\
Extended right hemicolectomy & $48(4.5 \%)$ & $8(3.3 \%)$ & $3(3.6 \%)$ \\
Left hemicolectomy & $24(2.3 \%)$ & $6(2.4 \%)$ & $4(4.8 \%)$ \\
Sigmoid colectomy & $34(3.2 \%)$ & $16(6.5 \%)$ & $4(4.8 \%)$ \\
Anterior resection & $467(44.2 \%)$ & $136(55.3 \%)$ & $40(47.6 \%)$ \\
Abdominoperineal excision & $41(3.9 \%)$ & $11(4.5 \%)$ & $10(11.9 \%)$ \\
Hartman's procedure & $21(2 \%)$ & $4(1.6 \%)$ & $2(2.4 \%)$ \\
other & $141(13.4 \%)$ & $24(9.8 \%)$ & $5(6 \%)$ \\
\hline
\end{tabular}


Table 3 Perioperative characteristics and outcomes

\begin{tabular}{lllll}
\hline & Non-obese $(n=1056)$ & Obese $(n=246)$ & Morbidly obese $(n=84)$ & $p$ value \\
\hline Median operative time $(\min )$ & $170(125-210)$ & $188(145-240)$ & $185(145-210)$ & $20(10-50)$ \\
Median estimated blood loss $(\mathrm{ml})$ & $10(0-20)$ & $20(0-45)$ & 0 & $\mathbf{0 . 0 0 0}^{\mathrm{a}}$ \\
Conversion to open & $11(1 \%)$ & $5(2 \%)$ & $\mathbf{0 . 0 0 3}^{\mathrm{a}}$ \\
\hline
\end{tabular}

Statistically significant values are given in bold

${ }^{\mathrm{a}}$ Kruskal-Wallis Test

${ }^{\mathrm{b}}$ Chi-square

Table 4 Post-operative clinical and pathological outcomes

Table 5 Univariate and multivariate logistic regression for conversion

\begin{tabular}{lllll}
\hline & Non-obese $(n=1056)$ & Obese $(n=246)$ & Morbidly obese $(n=84)$ & $p$ value \\
\hline Median length of stay (days) & $4(3-7)$ & $5(3-7)$ & $4(3-7)$ & $0.454^{\mathrm{a}}$ \\
30-day readmission & $115(10.9 \%)$ & $28(11.4 \%)$ & $14(16.7 \%)$ & $0.274^{\mathrm{b}}$ \\
30-day reoperation & $31(2.9 \%)$ & $5(2 \%)$ & $4(4.8 \%)$ & $0.427^{\mathrm{b}}$ \\
30-day mortality & $5(0.5 \%)$ & 0 & 0 & $0.454^{\mathrm{b}}$ \\
Anastomotic leak & $14(1.5 \%)$ & $3(1.3 \%)$ & $2(2.8 \%)$ & $0.663^{\mathrm{b}}$ \\
Median lymph node yield & $16.5(12-23)$ & $16(11-23)$ & $18(14-22.75)$ & $0.267^{\mathrm{a}}$ \\
R0 clearance & $743(94.8 \%)$ & $190(98.4 \%)$ & $66(100 \%)$ & $0.079^{\mathrm{b}}$ \\
\hline
\end{tabular}

${ }^{\text {a }}$ Kruskal-Wallis Test

${ }^{c}$ Chi-square

\begin{tabular}{|c|c|c|c|c|c|c|}
\hline & \multicolumn{3}{|c|}{ Univariate } & \multicolumn{3}{|c|}{ Multivariate } \\
\hline & OR & $95 \% \mathrm{CI}$ & $p$ value & $\mathrm{OR}$ & $95 \% \mathrm{CI}$ & $p$ value \\
\hline BMI & 1.016 & $0.927-1.114$ & 0.731 & 1.029 & $0.935-1.133$ & 0.556 \\
\hline Age & 1.006 & $0.973-1.040$ & 0.714 & 1.023 & $0.985-1.063$ & 0.241 \\
\hline ASA grade & 0.965 & $0.422-2.205$ & 0.933 & 0.844 & $0.357-1.996$ & 0.700 \\
\hline Mode of surgery (emergency) & 0.498 & $0.064-3.852$ & 0.504 & 0.483 & $0.059-3.916$ & 0.495 \\
\hline Diagnosis (malignant) & 1.839 & $0.663-5.098$ & 0.241 & 2.592 & $0.818-8.211$ & 0.105 \\
\hline
\end{tabular}

$O R$ odds ratio, $C I$ confidence interval

\begin{tabular}{|c|c|c|c|c|c|c|}
\hline & \multicolumn{3}{|c|}{ Univariate } & \multicolumn{3}{|c|}{ Multivariate } \\
\hline & OR & $95 \% \mathrm{CI}$ & $p$ value & OR & $95 \% \mathrm{CI}$ & $p$ value \\
\hline BMI & 1.011 & $0.981-1.041$ & 0.492 & 1.005 & $0.975-1.037$ & 0.738 \\
\hline Age & 0.994 & $0.985-1.004$ & 0.233 & 0.994 & $0.982-1.007$ & 0.356 \\
\hline ASA grade & 1.222 & $0.938-1.590$ & 0.137 & 1.298 & $0.975-1.728$ & 0.074 \\
\hline Mode of surgery (emergency) & 0.719 & $0.330-1.569$ & 0.408 & 0.777 & $0.349-1.732$ & 0.537 \\
\hline Diagnosis (malignant) & 1.302 & $0.925-1.302$ & 0.130 & 1.197 & $0.789-1.815$ & 0.398 \\
\hline
\end{tabular}

$O R$ odds ratio, $C I$ confidence interval
Table 6 Univariate and multivariate logistic regression for morbidity and mortality
BMI $\geq 40$ group but this was not statistically significant (180 vs $194 \mathrm{~min} ; p=0.142$ ).

\section{Right colonic, left colonic and rectal resections}

There was a total of 396 patients that received right colon, 88 left colon and 732 rectal resections. The remaining patients received a combination of subtotal colectomies, proctocolectomies and panproctocolectomies.

For the right colonic resections, the results were similar to those of the overall cohort, although operation time and blood loss did not reach statistical significance (morbidly obese vs obese vs non-obese: median operation time 125 vs 125 vs $115 \mathrm{~min}, p=0.101$; median estimated blood loss 20 vs 20 vs $10 \mathrm{ml}, p=0.065)$. There were no observed 
Fig. 1 Scatter plot of BMI against operative time

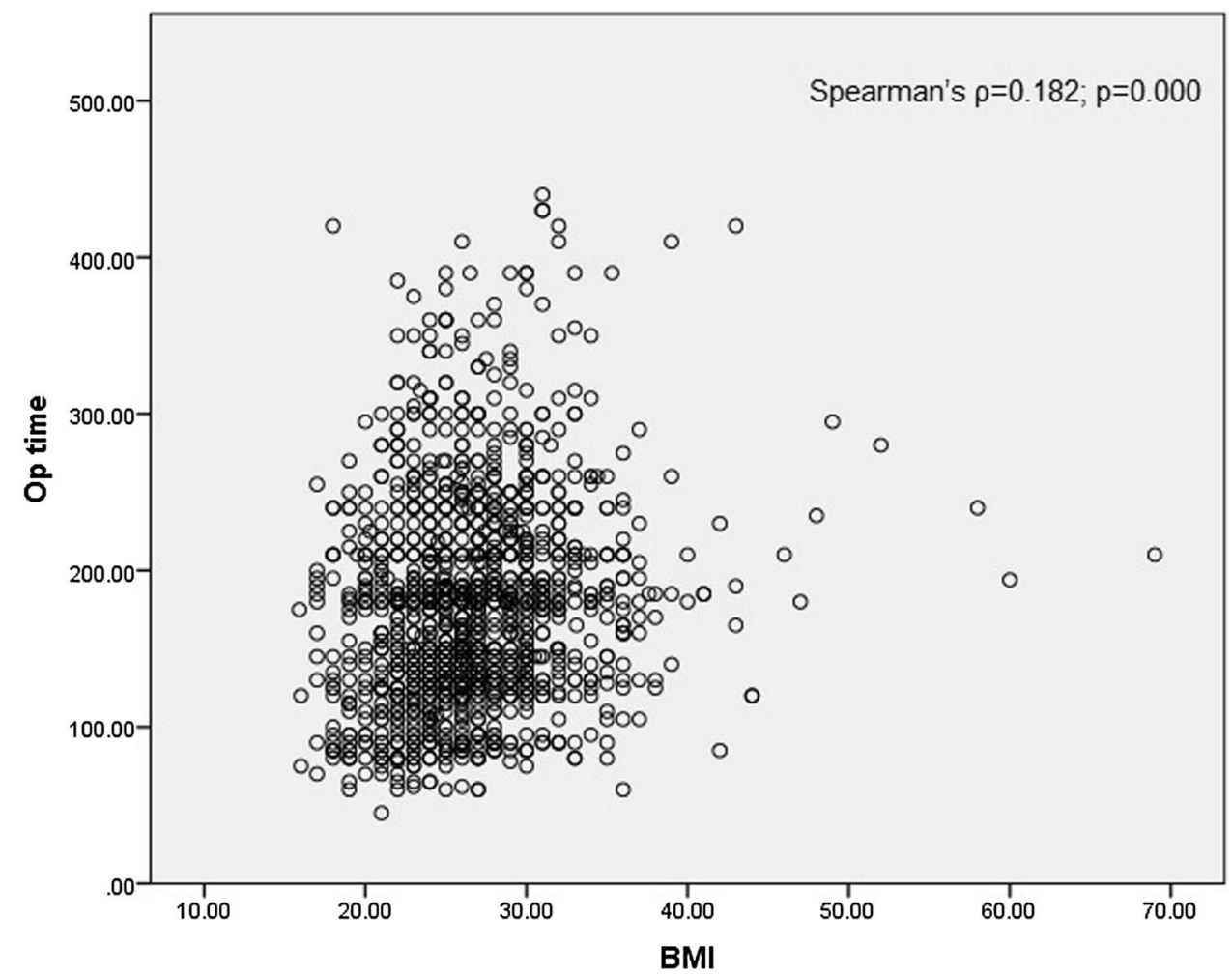

Table 7 Univariate and multivariate linear regression for operative time

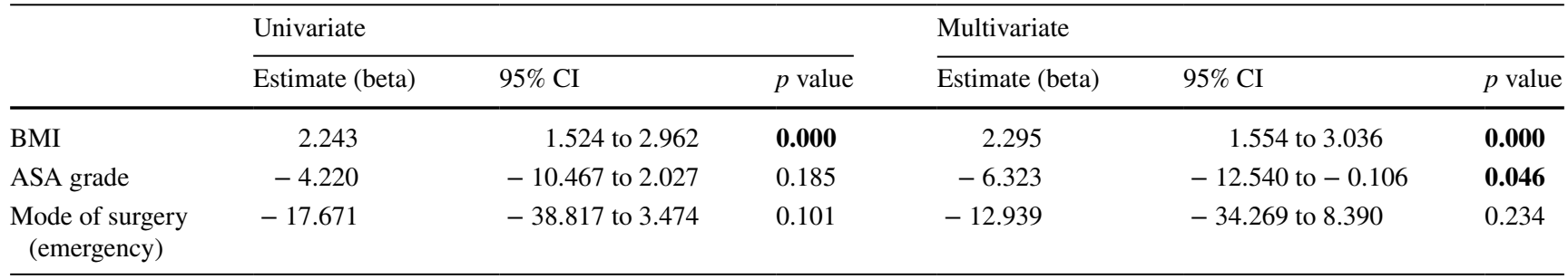

Statistically significant values are given in bold

CI confidence interval

Correlation for BMI: Spearman's $\rho=0.182 ; p=0.000$

differences in terms of baseline characteristics or shortterm surgical outcomes between the three cohorts in left colonic resections.

In rectal resections, results reflected again those of the overall cohort results (ASA higher with increasing BMI, operation time and blood loss higher in obese and morbidly obese groups) and there were no differences in any of the short-term post-operative outcomes between the three groups with the exception of readmission rate, which was higher in the morbidly obese group (non-obese vs obese vs morbidly obese: $10.2,9.9$, and $23.1 \% ; p=0.016$ ).

\section{Discussion}

Morbid obesity is becoming increasingly more common and the surgical outcomes of this group of patients warrant further investigation $[15,16]$. In this study, we have found that the increased technical difficulty encountered in obese and morbidly obese patients in minimally invasive colorectal surgery results in higher operative times and blood loss. However, conversion rate, length of stay, 30-day readmission, 30-day reoperation, anastomotic leak and 30-day mortality rates were similar between nonobese, obese and morbidly obese patients. In addition, our results demonstrate that in cancer patients there were no differences in lymph node yield and CRM (R0) clearance 
rates between the three cohorts. Furthermore, BMI was not found to affect conversion rate or morbidity and mortality on logistic regression analysis. These findings strengthen the argument that by standardising operative technique and post-operative care minimally invasive surgery for the morbidly obese and obese is safe, feasible and does not result in higher surgical morbidity.

In our study we found that operative time and estimated blood loss were higher in the obese and morbidly obese groups. However, the operative time and blood loss of the obese and morbidly obese groups were similar. This is different to what we anticipated, since the increasing technical difficulty associated with operating on the morbidly obese patients was expected to result in even longer operative times and higher blood loss. Furthermore, it should be noted that although statistically significant, the differences in operative time and blood loss are not clinically significant. Patients in the obese and morbidly obese groups took an extra $15 \mathrm{~min}$ to operate on and had an additional $10 \mathrm{mls}$ of blood loss. Considering the median operative time for the non-obese was over $3 \mathrm{~h}$, the longer operative time and higher blood loss encountered in the obese and morbidly obese are unlikely to significantly affect the patient's clinical outcomes as our results infers.

Our results are in accordance with a recently published meta-analysis [10] examining the outcomes of obese vs nonobese laparoscopic colorectal surgery patients. This study combined the data of 13 and 6 studies for operative time and blood loss respectively and found that both parameters were higher in the obese group, by an average of $13 \mathrm{~min}$ and 34 $\mathrm{mls}$, respectively. The operative time and blood loss of obese vs non-obese patients receiving laparoscopic colorectal surgery was also examined in a recently published systematic review including 30 studies [13]. In this review it is clear that there is great variability in reported outcomes. Regarding operative time 18 studies reported longer operative times in the obese vs 12 that did not. In terms of estimated blood loss, 8 studies reported higher blood loss in the obese and 8 found no difference between the two groups. The differences in reported outcomes are probably multifactorial. First of all, studies failing to demonstrate a difference could be doing so due to a type 2 error. This is because the actual differences are small and therefore a large sample size is required to demonstrate a statistically significant difference in outcomes. A second reason might be variability in surgical practise. The operative technique and experience of some surgeons might be better adapted to cope with the increased technical difficulties of obese patients, therefore making less likely to demonstrate any differences in surgical outcomes.

In our study, we found that BMI was as independent factor for operative time as demonstrated in linear regression analysis. Although the actual correlation was weak $(\rho=0.182)$, it was statistically significant and linear regression analysis showed that for every increase in one unit of BMI operative time increased by roughly $2 \mathrm{~min}$. We are not the first study to demonstrate that BMI is an independent predicting factor for operative time, with three previously published studies demonstrating similar results [22-24], one of which compared the operative times of morbidly obese $(\mathrm{BMI} \geq 35)$ patients to non-obese patients [22].

Apart from operative time and blood loss, there were no statistically significant differences in short-term surgical outcomes between the three groups. This is opposite to what one might expect, considering again the increased technical difficulties encountered when operating on obese and even more so on morbidly obese patients. Multiple previous studies (including systematic reviews and meta-analysis) have shown that obesity is associated with a higher conversion rate, anastomotic leak rate, increased post-operative morbidity and a lower lymph node yield in minimally invasive surgery [10-12, 25]. However, several studies have reported similar short-term surgical outcomes between obese and non-obese patients $[9,13,14]$. Just as for operative time and blood loss, the reasons behind this are probably multifactorial. Variability in surgical practice, surgeon experience and centre volume can all effect surgical outcomes. Furthermore, small sample sizes and small outcome differences reduce the prospect of demonstrating a statistically significant difference. We believe that by standardising operative technique and breaking down surgical procedures in digestible modules we enhance reproducibility of results and facilitate surgical training. This way, surgical outcomes are fairly similar, regardless of perioperative conditions. This could account for the similar short-term surgical outcomes in our patients, regardless of their obesity level.

Only a handful of studies have specifically examined the morbidly obese [14, 25-27], most of them using a cut-off of $\mathrm{BMI} \geq 40[14,25,26]$. Hussan et al. examined 85,300 discharges of colorectal cancer surgery patients from the US 2012 National Inpatient Sample and found that morbid obesity was associated with a higher prevalence of perioperative comorbidities, surgical complications, conversions to open, perioperative mortality and prolonged length of stay [25]. However, it should be noted that in this study $70 \%$ of patients received open surgery. In contrast, Khoury et al. [14] specifically examined the feasibility of laparoscopic surgery in the morbidly obese. In this study, there was no statistical difference in any surgical outcomes between the morbidly obese and non-obese (36 vs 36 patients) apart from skin incision length. However, the authors have reported a trend towards worse short-term outcomes in the morbidly obese group. This could be suggested with some of our results. Readmission, reoperation and anastomotic leak rates appear higher in the morbidly obese group when compared to the obese and non-obese groups (Table 4). Nonetheless, these differences are small and not statistically significant. In 
addition, when examining whether BMI affected conversion rate or morbidity and mortality in a logistic regression model no association was demonstrated.

A recently published American study by Champagne et al. examined the outcomes of obese patients having laparoscopic colectomies based on the degree of obesity [26]. In this study, obese patients were divided in three groups (obese, morbidly obese and super-obese) and had their outcomes evaluated. This manuscript concluded that increasing obesity severity correlated with worse perioperative outcomes. However, the majority of the short-term outcomes presented (operative time, conversion rate, post-operative morbidity and length of stay) are similar between the obese and morbidly obese groups, with these outcomes only worsening in the super-obese group (BMI $\geq 50$ ). In terms of the morbidly obese, their results are similar to our findings, demonstrating no real differences between morbidly obese and obese patients. The worse short-term outcomes presented in the super-obese group could be secondary to the greatly increased visceral adiposity and abdominal wall size, further adding to the technical complexity of the operation. In our study population evaluation of the super-obese surgical outcomes was prohibited due to the small sample size $(n=4)$.

Subgroup analysis of the data according to right colon, left colon and rectal resections widely demonstrated similar results to those of the overall cohort. However, it should be noted that readmission rate was higher in the morbidly obese group for rectal resections, while similar between the obese and non-obese groups. It might be that in patients with morbid obesity (BMI $\geq 35)$ rectal resection presents a technical challenge of even tighter pelvic space occupied by a rather large mesorectum which may result in even greater intraoperative difficulty, leading to higher morbidity reflected by a higher readmission rate. However, this is an isolated positive finding that was not reconfirmed in logistic regression analysis (data not shown).

The main strengths of this study are its large sample size, the fact that data were collected from three centres from two different countries and the fact that all three participating surgeons follow the same modular standardised operative techniques. However, as with all research there are specific limitations that should be duly recognised and acknowledged. Despite collecting data from prospectively collated databases, the study design was retrospective in nature. However, collecting data from prospectively maintained databases minimises observation bias and by including all consecutive patients' selection bias is minimised. Secondly, we have defined morbid obesity as BMI $\geq 35$ in accordance with the NIH conference [17]. However, many studies examining morbid obesity use BMI 40 as a cut-off. Although a BMI $\geq 40$ would better allow us to evaluate the effect of an ever-increasing BMI on surgical outcomes, we only had a small number of patients with $\mathrm{BMI} \geq 40(n=20)$. A subgroup analysis of patients with $35 \leq \mathrm{BMI}<40 \mathrm{vs} \mathrm{BMI} \geq 40$ showed no significant differences between the two groups, but results should be taken with caution due to the small sample size. A further limitation in our study is that there are differences in the baseline characteristics in terms of ASA grade, mode of surgery and gender between the three examined cohorts. ASA grade increased across the obesity categories as one would expect, but the differences in gender and mode of surgery appear random. Nevertheless, the differences in gender and mode of surgery are relatively small. Moreover, ASA grade and mode of surgery have been accounted for in the multivariate logistic regression analysis.

In summary, our study's findings show that minimally invasive colorectal surgery is safe and feasible regardless of BMI when operative technique and perioperative care are standardised. The increased operative time and blood loss observed in the obese and morbidly obese are of no clinical significance and have not been proved to affect the rest of the short-term surgical outcomes. Therefore, this group of patients is likely to benefit from the advantages offered by minimally invasive surgery. Larger scale multi-centre observational studies are required to determine the outcomes of morbidly obese patients receiving minimally invasive colorectal surgery.

Funding No funding was received to produce or support this technical note.

\section{Compliance with ethical standards}

Disclosures Prof A Parvaiz is a proctor EARCS (European Academy of Robotic Colorectal Surgery) which is funded by Intuitive Surgical. Mr S Panteleimonitis, Dr S Popeskou, Dr M Harper, Dr N Kandala, Dr N Figueiredo and Prof T Qureshi have no conflicts of interest or financial ties to disclose.

Open Access This article is distributed under the terms of the Creative Commons Attribution 4.0 International License (http://creativecommons.org/licenses/by/4.0/), which permits unrestricted use, distribution, and reproduction in any medium, provided you give appropriate credit to the original author(s) and the source, provide a link to the Creative Commons license, and indicate if changes were made.

\section{References}

1. Jayne DG, Thorpe HC, Copeland J, Quirke P, Brown JM, Guillou PJ (2010) Five-year follow-up of the Medical Research Council CLASICC trial of laparoscopically assisted versus open surgery for colorectal cancer. Br J Surg 97:1638-1645. https://doi. org/10.1002/bjs.7160

2. Kennedy RH, Francis EA, Wharton R, Blazeby JM, Quirke P, West NP, Dutton SJ (2014) Multicenter randomized controlled trial of conventional versus laparoscopic surgery for colorectal cancer within an enhanced recovery programme: EnROL. J Clin Oncol 32:1804-1811. https://doi.org/10.1200/JCO.2013.54.3694 
3. Veldkamp R, Kuhry E, Hop WC, Jeekel J, Kazemier G, Bonjer HJ, Haglind E, Pahlman L, Cuesta MA, Msika S, Morino M, Lacy AM (2005) Laparoscopic surgery versus open surgery for colon cancer: short-term outcomes of a randomised trial. Lancet Oncol 6:477-484. https://doi.org/10.1016/s1470-2045(05)70221-7

4. Van der Pas MH, Haglind E, Cuesta MA, Furst A, Lacy AM, Hop WC, Bonjer HJ, Fürst A, Lacy AM, Hop WC, Bonjer HJ, COlorectal cancer Laparoscopic or Open Resection II (COLOR II) Study Group (2013) Laparoscopic versus open surgery for rectal cancer (COLOR II): short-term outcomes of a randomised, phase 3 trial. Lancet Oncol 14:210-218. https://doi.org/10.1016/ S1470-2045(13)70016-0

5. Kang S-BB, Park JW, Jeong S-YY, Nam BH, Choi HS, Kim D-HD-WDYD-WD-HYHWD-W, Lim S-BB, Lee T-GG, Kim D-HD-WDYD-WD-HYHWD-W, Kim JHJ-SSJH, Chang HJ, Lee H-SS, Kim SY, Jung KH, Hong YS, Kim JHJ-SSJH, Sohn DK, Kim D-HD-WDYD-WD-HYHWD-W, Oh JH (2010) Open versus laparoscopic surgery for mid or low rectal cancer after neoadjuvant chemoradiotherapy (COREAN trial): short-term outcomes of an open-label randomised controlled trial. Lancet Oncol 11:637-645. https://doi.org/10.1016/S1470-2045(10)70131-5

6. Jeong S-YY, Park JW, Nam BH, Kim SYS, Kang S-BB, Lim S-BB, Choi HS, Kim D-HD-WDYDWDH, Chang HJ, Kim D-HDWDYDWDH, Jung KH, Kim T-YY, Kang GH, Chie EK, Kim SYS, Sohn DK, Kim D-HD-WDYDWDH, Kim JHJ-SS., Lee HS, Kim JHJ-SS., Oh JH (2014) Open versus laparoscopic surgery for mid-rectal or low-rectal cancer after neoadjuvant chemoradiotherapy (COREAN trial): Survival outcomes of an open-label, noninferiority, randomised controlled trial. Lancet Oncol 15:767-774. https://doi.org/10.1016/S1470-2045(14)70205-0

7. Merkow RP, Bilimoria KY, McCarter MD, Bentrem DJ (2009) Effect of body mass index on short-term outcomes after colectomy for cancer. J Am Coll Surg 208:53-61. https://doi.org/10.1016/j. jamcollsurg.2008.08.032

8. Lascano C, Kaidar-Person O, Szomstein S, Rosenthal R, Wexner SD (2006) Challenges of laparoscopic colectomy in the obese patient: a review. Am J Surg 192:357-365. https://doi. org/10.1016/j.amjsurg.2006.04.011

9. Harr JN, Luka S, Kankaria A, Juo Y-YY, Agarwal S, Obias V (2017) Robotic-assisted colorectal surgery in obese patients: a case-matched series. Surg Endosc Other Interv Tech 31:28132819. https://doi.org/10.1007/s00464-016-5291-1

10. He Y, Wang J, Bian H, Deng X, Wang Z (2017) BMI as a predictor for perioperative outcome of laparoscopic colorectal surgery: a pooled analysis of comparative studies. Dis Colon Rectum 60:433-445. https://doi.org/10.1097/DCR.0000000000000760

11. Fung A, Trabulsi N, Morris M, Garfinkle R, Saleem A, Wexner SD, Vasilevsky CA, Boutros M (2017) Laparoscopic colorectal cancer resections in the obese: a systematic review. Surg Endosc Other Interv Tech 31:2072-2088. https://doi.org/10.1007/ s00464-016-5209-y

12. Yang T, Wei M, He Y, Deng X, Wang Z (2015) Impact of visceral obesity on outcomes of laparoscopic colorectal surgery: A meta-analysis. ANZ J Surg 85:507-513. https://doi.org/10.1111/ ans. 13132

13. Ribas H, Zakeri Y, Nunes S, Murphy QM, Bhan J, Wexner C SD (2016) The influence of obesity and body mass index on the outcome of laparoscopic colorectal surgery: a systematic literature review. Color Dis 18:O337-O366. https://doi.org/10.1111/ codi.13406

14. Khoury W, Kiran RP, Jessie T, Geisler D, Remzi FH (2010) Is the laparoscopic approach to colectomy safe for the morbidly obese? Surg Endosc Other Interv Tech 24:1336-1340. https:// doi.org/10.1007/s00464-009-0770-2

15. Ogden CL, Carroll MD, Kit BK, Flegal KM (2012) Prevalence of obesity in the United States, 2009-2010. Nutrition. https://doi. org/10.1001/jama.2014.6228

16. Hscic (2014) Statistics on obesity, physical activity and diet Heal San Fr 1:112. 978-1-84636-274-3

17. (1991) NIH conference. Gastrointestinal surgery for severe obesity. Consensus Development Conference Panel. Ann Intern Med 115:956-961

18. Miskovic D, Foster J, Agha A, Delaney CP, Francis N, Hasegawa H, Karachun A, Kim SH, Law WL, Marks J, Morino M, Panis Y, Uriburu JCP, Wexner SD, Parvaiz A (2015) Standardization of laparoscopic total mesorectal excision for rectal cancer: a structured international expert consensus. Ann Surg 261:716-722. https://doi.org/10.1097/SLA.0000000000000823

19. Hemandas A, Flashman KG, Farrow J, O'Leary DP, Parvaiz A (2011) Modular training in laparoscopic colorectal surgery maximizes training opportunities without clinical compromise. World J Surg 35:409-414. https://doi.org/10.1007/s00268-010-0837-1

20. Ahmed J, Panteleimonitis S, Parvaiz A (2016) Modular approach for single docking robotic colorectal surgery. J Vis Surg 2:109109. https://doi.org/10.21037/jovs.2016.06.07

21. Kehlet H, Wilmore DW (2002) Multimodal strategies to improve surgical outcome. Am J Surg 183:630-641

22. Saiganesh H, Stein DE, Poggio JL (2014) Body mass index predicts operative time in elective colorectal procedures. J Surg Res 197:45-49. https://doi.org/10.1016/j.jss.2015.02.067

23. Mustain WC, Davenport DL, Hourigan JS, Vargas HD (2012) Obesity and laparoscopic colectomy. Dis Colon Rectum 55:429435. https://doi.org/10.1097/DCR.0b013e31823dfb17

24. Makino T, Trencheva K, Shukla PJ, Rubino F, Zhuo C, Pavoor RS, Milsom JW (2014) The influence of obesity on short- and long-term outcomes after laparoscopic surgery for colon cancer: a case-matched study of 152 patients. Surg 156:661-668. https:// doi.org/10.1016/j.surg.2014.03.023

25. Hussan H, Gray DM, Hinton A, Krishna SG, Conwell DL, Stanich PP (2016) Morbid Obesity is Associated with Increased Mortality, Surgical Complications, and Incremental Health Care Utilization in the Peri-Operative Period of Colorectal Cancer Surgery. World J Surg 40:987-994. https://doi.org/10.1007/s00268-015-3358-0

26. Champagne BJ, Nishtala M, Brady JT, Crawshaw BP, Franklin ME, Delaney CP, Steele SR (2017) Laparoscopic colectomy in the obese, morbidly obese, and super morbidly obese: when does weight matter?. Int J Colorectal Dis. https://doi.org/10.1007/ s00384-017-2865-x

27. Scheidbach H, Benedix F, Hügel O, Kose D, Köckerling F, Lippert $\mathrm{H}$ (2008) Laparoscopic approach to colorectal procedures in the obese patient: risk factor or benefit? Obes Surg 18:66-70. https:// doi.org/10.1007/s11695-007-9266-0 